\title{
Butylated Hydroxyanisole
}

National Cancer Institute

\section{Source}

National Cancer Institute. Butylated Hydroxyanisole. NCI Thesaurus. Code C44347.

A white, waxy solid mixture of 2- and 3-T ert-butyl-4-hydroxyanisole with a faint aromatic odor. Butylated Hydroxyanisole is a widely used synthetic antioxidant in foods, cosmetics and pharmaceuticals mainly to preserve fats and oils. Butylated Hydroxyanisole is reasonably anticipated to be a human carcinogen. ( $\mathrm{NCI05)}$ 